\title{
Integrating gamma log and conventional electrical logs to improve identification of fracture zones in hard rocks for hydrofracturing: a case study from Ghana
}

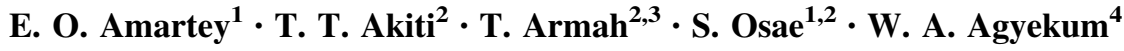

Received: 14 June 2012/ Accepted: 15 July 2016/Published online: 25 July 2016

(c) The Author(s) 2016. This article is published with open access at Springerlink.com

\begin{abstract}
Hydrofracturing of low-yielding boreholes in hard rocks is a widely used technique in Africa for improvement of yield, thus making them qualified for installation of a hand-pump for domestic water supply. However, the success rate of the hydrofracturing campaigns seems not to be that high as generally claimed by contractors. One reason amongst others might be that the selection of zones for hydrofracturing in the individual borehole is based on pre-hydrofracturing investigation using conventional electrical logs only. Thereby, the zones selected are the occurring resistivity minima interpreted as weak zones with some fracturing. However, resistivity minima can also be caused solely by lithological reasons, which then in most cases could have been seen on a gamma $\log$ as corresponding increased gamma radiation. The advantages of using gamma logging in combination with conventional electrical logging technique for prediction of fractured zones in basement rocks is illustrated by investigations of three low-yielding boreholes located in different geological environments in crystalline basement rocks in Ghana.
\end{abstract}

E. O. Amartey

edalaska2000@yahoo.com

1 National Nuclear Research Institute, Ghana Atomic Energy Commission (GAEC), Accra, Ghana

2 Graduate School of Nuclear and Allied Sciences, University of Ghana, Legon, Ghana

3 Earth Science Department, University of Ghana, Legon, Ghana

4 Council for Scientific and Industrial Research (CSIR), Water Research Institute, Accra, Ghana
Keywords Groundwater - Gamma radiation - Borehole logging · Fracture zone $\cdot$ Hard rock · Ghana

\section{Introduction}

Crystalline basement rocks are igneous or metamorphic rocks, where the inter-granular pore spaces are negligible and almost all groundwater flow takes place through cracks and fractures in the rocks (Banks and Robins 2002; Wright, 1992). In Ghana groundwater has proven to be the most economic and feasible source of portable water to dispersed rural communities (Gyau-Boakye and Dapaah-Siakwan 1999) and towns, which are not easily accessible to or with inadequate supply of treated surface water. Groundwater availability within the weathered and deeper fracture zones depend on the thickness and extension of the fractured sections, sustainable and the relative depth of the water table. The thicker the weathering profile, the more sustainable the water-bearing potential. However, due to the complex interactions of the various factors affecting weathering and fracturing, water-bearing zones may not be present at all at some locations (MacDonald and Davies 2000). These fracture zones in hard rock environment play an essential and critical role in fluid flow within the subsurface, such as the movement and accumulation of groundwater as well as transport of contaminants (Karous and Mares 1988). Geophysical borehole logging is a subsurface technique that has applications in a wide range of fields such as geotechnical, hydrogeological, mining or hydrocarbon investigations. Its application can be found in areas such as identification of lithology and correlating stratigraphy where cores have not been recovered from all of the boreholes at the site (Monier-Williams et al. 2009). According to Telford et al. (1990) electrical $\log$ is the

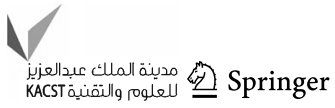


oldest geophysical logging technique that measures the formation electrical properties in the vicinity of the borehole. It is important to note that conventional electrical logging can only be run in open fluid-filled portion of the borehole (Keys 1997). Among the electrical logging suite are the resistivity and SPR logs which can investigate the formation resistivity and resistance, respectively, of a geologic medium (Telford et al. 1990). They can be used to identify fractures or shear zones that may contain water or conductive minerals (e.g., graphite, massive sulfides, etc.) in hard rocks (Telford et al. 1990). These borehole logging tools offer one of the most reliable ways of detecting fractured sections intercepted by the borehole, since some of these fractures may be masked and detected as a single anomaly during a surface geophysical measurements (Agyekum 2009; Awini 2009; Ratnakar and Singh 2008; Krishnamurthy et al. 2003; Lee et al. 1991; Lee 1985). Gamma log is an important and standard nuclear radiation logging tool, which can be operated in both cased and opened boreholes filled with air, water or drilling fluid, giving them an advantage over electrical logging suites (Kearey et al. 2002; Driscoll 1986). The gamma log device is a passive system without a radioactive source and it provides a continuous record of the amount of natural gamma radiation emitted by the intercepted geologic material of the borehole. It is generally used as one of the primary tool for lithological investigation (Keys 1997). For instance in Ghana, Agyekum et al. (2013) deployed the natural gamma detectors embedded in the five exploratory logging tools to investigate significant discrepancies between the logging results and the driller's/geologist's logs results on reported drilled depths, construction depths, and screen settings of boreholes in the Voltaian sedimentary rocks.

The combined application of these borehole logging tools is exploited in this investigation to distinguish between lithological boundaries and fractured zones in boreholes drilled in the hard rocks within the study areas for the purpose of hydrofracturing. Prior to the hydrofracturing process, the potential micro-fracture zones are identified based on the logging results. In an open borehole below the water table, pressurized water is introduced into the identified micro-fracture sections to create, sustain and reopen tensile fractures in the hard rocks (Ramstad 2004; Monier-Williams et al. 2009) to improve the yield.

\section{Geology and hydrogeology of the study areas}

Figure 1 presents the location map of the three (3) study areas: Ghana Atomic Energy Commission (GAEC) compound at Kwabenya $\left(5^{\circ} 40.0^{\prime} \mathrm{N}, 0^{\circ} 13.0^{\prime} \mathrm{W}\right)$, Water Research Institute (WRI) compound $\left(5^{\circ} 35.7^{\prime} \mathrm{N}, 0^{\circ} 11.0^{\prime} \mathrm{W}\right)$ located in the Accra Plains of Ghana, whilst the third study area,
Buokrom is located on $5^{\circ} 51.0^{\prime} \mathrm{N}, 0^{\circ} 20.0^{\prime} \mathrm{W}$ within the Densu River Basin in the Eastern Region. Kwabenya area lies at the contact zone between Acidic Dahomeyan and rocks of Togo Series, while WRI is underlain by Acidic Dahomeyan rocks. The Acidic Dahomeyan rocks generally comprise muscovite-biotitic gneiss, quartz-feldspar gneiss, augen gneiss and minor amphibolites, which weather to slightly permeable calcareous clays (Kesse 1985). Rocks of Togo Series comprise highly folded arenaceous rocks of quartzite, mica-schist, quartz-schist, sandstone, shale, sericite-schist and phyllite. For these rocks, groundwater occurrence is mainly controlled by the development of secondary porosities such as the presence of fractures, joints and faults (Junner and Bates 1945). Buokrom and its immediate environs are mainly underlain by granitic rocks, which are associated with differentiated Birimian sequence. They are not inherently permeable but have secondary permeability or porosity developed as a result of fracturing, jointing and weathering, which may give rise to groundwater occurrence (Ahmed et al. 1977).

\section{Materials and methods}

The borehole logs were collected using MGX II logger from Mount Sopris Instrument Co. Inc., Golden, CO USA, and manually operated resistivity logger. Three boreholes located, respectively, at GAEC compound at Kwabenya, WRI premises in Accra and the Hydrometric Station of Earth Science Department, University of Ghana at Buokrom. The manually operated resistivity logging tool was used for the acquisition of the log data by mounting surface electrodes at $70 \mathrm{~m}$ for the current and $50 \mathrm{~m}$ for the potential electrodes, respectively. The borehole data for the resistivity logs were obtained by pulling the logger cable with the guide of a manual depth encoder at $1 \mathrm{~m}$ intervals. The resistance measured by the down-hole electrodes were displayed on the screen of the terrameter SAS 300C connected to the respective logger. The apparent resistivity values in Ohm-m were computed from the relation:

Apparent resistivity, $\rho_{a}=\frac{4 \pi \Delta V(\mathrm{AM})}{I}$

where $R=\frac{\Delta V}{I}$ is resistance of the formation, AM is the distance between the current and potential electrodes in the borehole (16" and 64") (Kearey et al. 2002) as shown in Fig. 2a. The effective volume of investigation for this normal resistivity device is a sphere with a radius equal to the separation between the $\mathrm{A}$ and $\mathrm{M}$ electrodes. The log represents a measurement of the average resistivity within that sphere of investigation (Telfold et al. 1990).

Because the radius of investigation is proportional to electrode spacing (AM), the short normal log is more 
Fig. 1 Location map showing the study areas GAEC, WRI and Buokrom

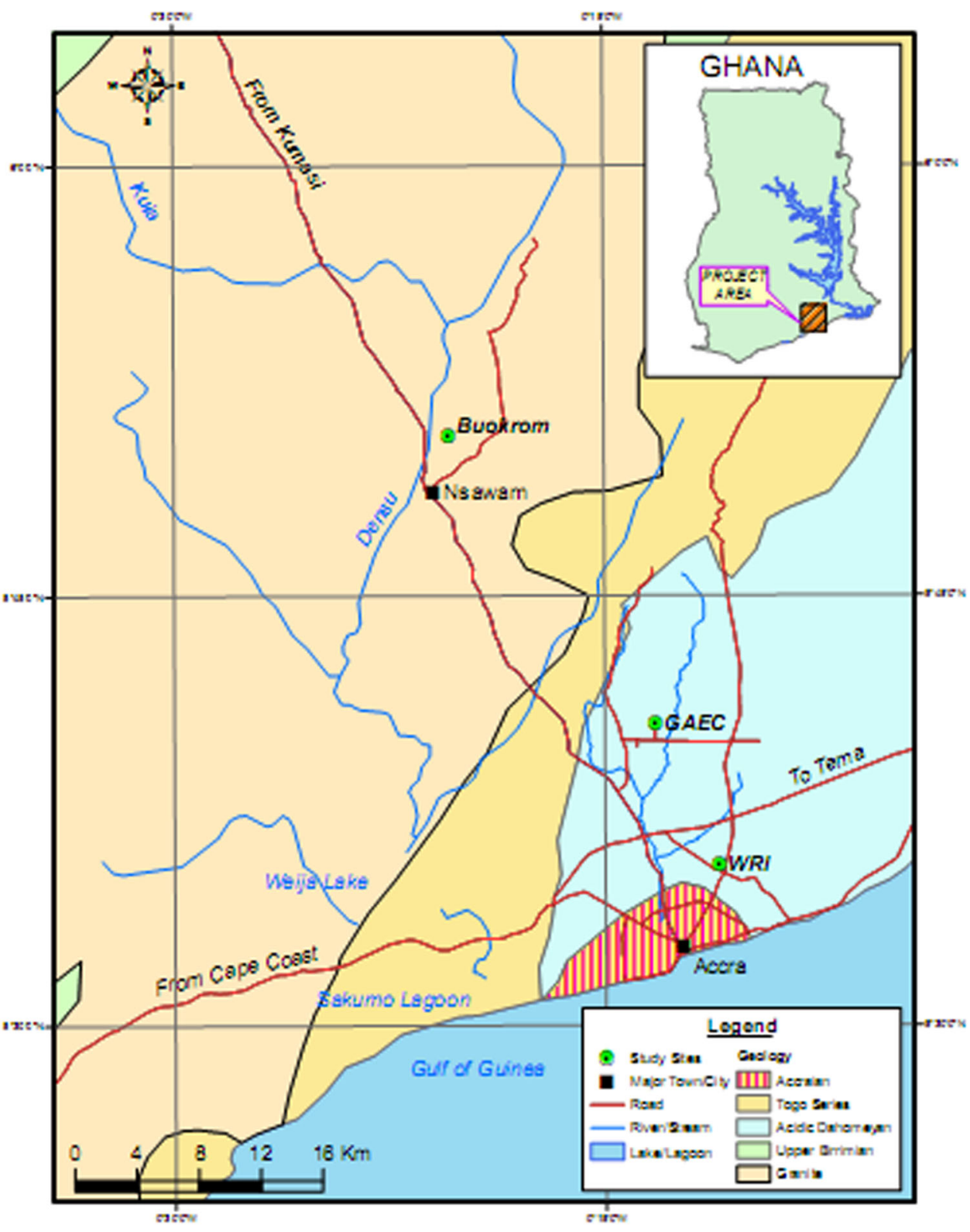

greatly influenced by the resistivity of the borehole fluid (zone of invasion) and is less likely to be a measure of true formation resistivity. The $\log$ response for the long normal $\log$ only provides a true formation resistivity if the bed thickness is significantly greater than the electrode separation (Kearey et al. 2002).

For the field set-up of the SPR, an electrode was placed at a distance of $70 \mathrm{~m}$ on the surface and the other electrode in the down-hole were connected to the MGX II logger with a constant current maintained between them, as shown in Fig. 2b. With the aid of Honda EP2500 generator supplying an alternating voltage of $220 \mathrm{~V}$, the appropriate panel settings were selected from the dashboard display of MSLog acquisition software (Mount Sopris Instrument Co. Inc. 2002a, b, c) for the acquisition of SPR and subsequently the natural gamma radiation count of the borehole formation. The resistance $(R)$ values in Ohm for the SPR $\log$ have the relation:

$R=\frac{4 \pi r \Delta V}{I}$

where $r$ is the radius of the single-point electrode in the borehole.

The set-up for the natural gamma log has the MGX II logger connected to the 2PGA-1000 Poly-Gamma probe (Mount Sopris Instrument Co. Inc. 2002b, c) for the acquisition of the gamma radiation counts. The gamma log detector converts incoming gamma radiation from the surrounding geologic formation into electrical impulses, which are proportional to the number of gamma rays 

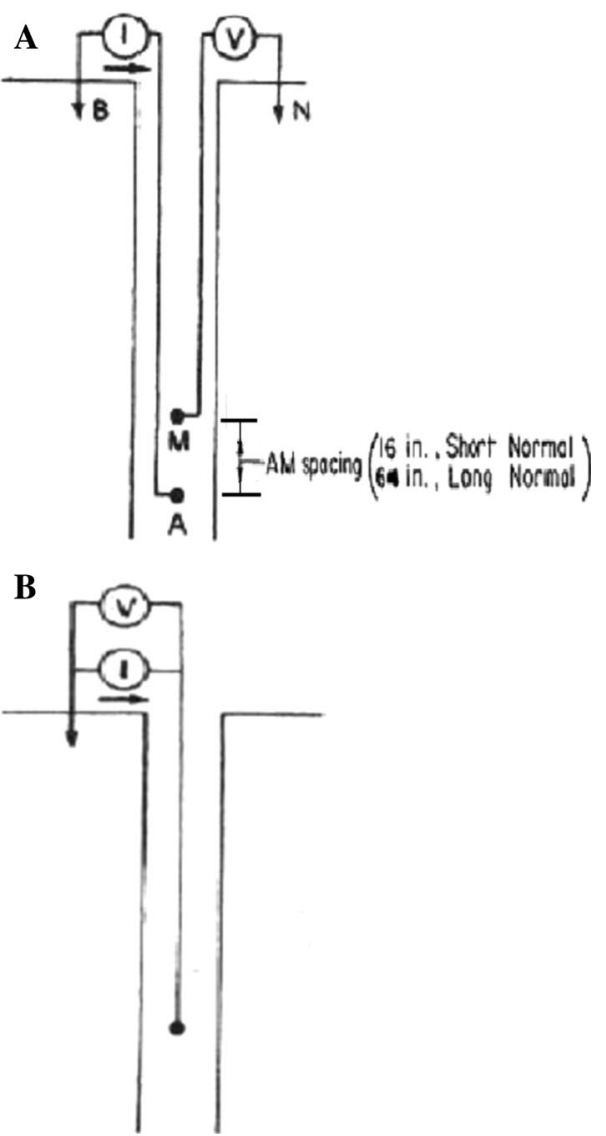

Fig. 2 a Electrodes set-up for normal resistivity logger. b Electrodes set-up for single-point resistance logger

detected and sends the amplified electrical impulses to the surface electronic device to be recorded and displayed. The static water level for each of the investigated boreholes was recorded before the logging process commenced.

\section{Results and discussions}

\section{GAEC compound}

The gamma log Fig. 3c clearly verifies the lithological log by showing great variation in radiation within the Togosequence down to $52 \mathrm{~m}$ depth, whereas the underlying normally rather homogeneous Dahomeyan rock below $52 \mathrm{~m}$ shows a generally higher radiation but with much less variation. The variation within the Togo-sequence should be interpreted as high radiation indicating schistose rock whereas low radiation indicates quarzitic rock.

The lithological log is not having any information on the weathered mantle other than the $6 \mathrm{~m}$ thick lateritic soil layer at the top, which is reflected on the three completely uniform electrical logs Fig. 3a and b, as having very low resistance/resistivities. However, the el-logs also indicate by still showing low, but slightly higher resistance/resistivities down to $14 \mathrm{~m}$ depth, marked by (a) on Fig. 3a and $\mathrm{b}$, that high degree of weathering continue into the upper part of the Togo-sequence. It is noteworthy that this $14 \mathrm{~m}$ thick mantle of lateritic soil and highly weathered, thus clayey rock with generally low resistance/resistivities does not correspond to a similar unambiguous pattern in the gamma radiation, e.g., a generally high radiation.

The transition to hard rock at approximately $15 \mathrm{~m}$ depth seems abrupt as indicated by the significant sharp increase in resistance/resistivities. The shift at $22 \mathrm{~m}$ depth, marked by (b) on Fig. 3a and b, to even higher resistance/resistivity values correspond to a significant change in gamma radiation pattern to a generally lower but more varying radiation probably reflecting a quarzitic sequence from that depth and downwards. The latter does also explain the shift to higher resistance/resistivities at $22 \mathrm{~m}$ depth without necessarily any occurrence of a fracture zone.

The highest resistance/resistivities $(100 \mathrm{Ohm} / 500 \mathrm{Ohm}$ $\mathrm{m} / 2000 \mathrm{Ohm}-\mathrm{m}$, respectively, on the three e-logs) are seen in the Dahomeyan rock from $52 \mathrm{~m}$ depth and downwards, though with slightly lower values at the bottom of the borehole, marked by (d) on Fig. 3a and b. The latter could indicate presence of fracturing and weathering at $71 \mathrm{~m}$ depth. Unfortunately, the gamma log stops at that depth, so whether the low values on the e-logs are caused by a lithological change or by fracturing and weathering cannot be evaluated.

Another section where the electrical logs do indicate presence of fracturing and weathering within the otherwise hard rock, is in the lower part of the Togo-sequence, i.e., between 40 and $50 \mathrm{~m}$ depth, where the resistance/resistivities are relatively low, marked by (c) on Fig. 3a and b. Though, since not lower than in the upper part of the fresh Togo-sequence from 15 to $22 \mathrm{~m}$ and also having the same high gamma radiation, the relatively lower resistance/resistivities between 40 and $50 \mathrm{~m}$ most probably is caused by a change in lithology from a quarzitic rock above $40 \mathrm{~m}$ to a schistose type of rock below $40 \mathrm{~m}$ depth and further down to the Dahomeyan at $52 \mathrm{~m}$ depth.

Conclusively, the combined interpretation of the electrical logs and the gamma log reveal that there is no clear indication of existence of any zone in this borehole favorable for hydro-fracturing neither within the Togo-sequence nor within the underlying Dahomeyan formation.

\section{WRI compound}

The limited variation of the gamma radiation on Fig. $4 \mathrm{c}$ is in accordance with the general perception that the Acid Dahomeyan rock is lithologically quite homogeneous. Therefore, in spite of not having any lithology record of the borehole, the gamma log verifies the expectation that the 


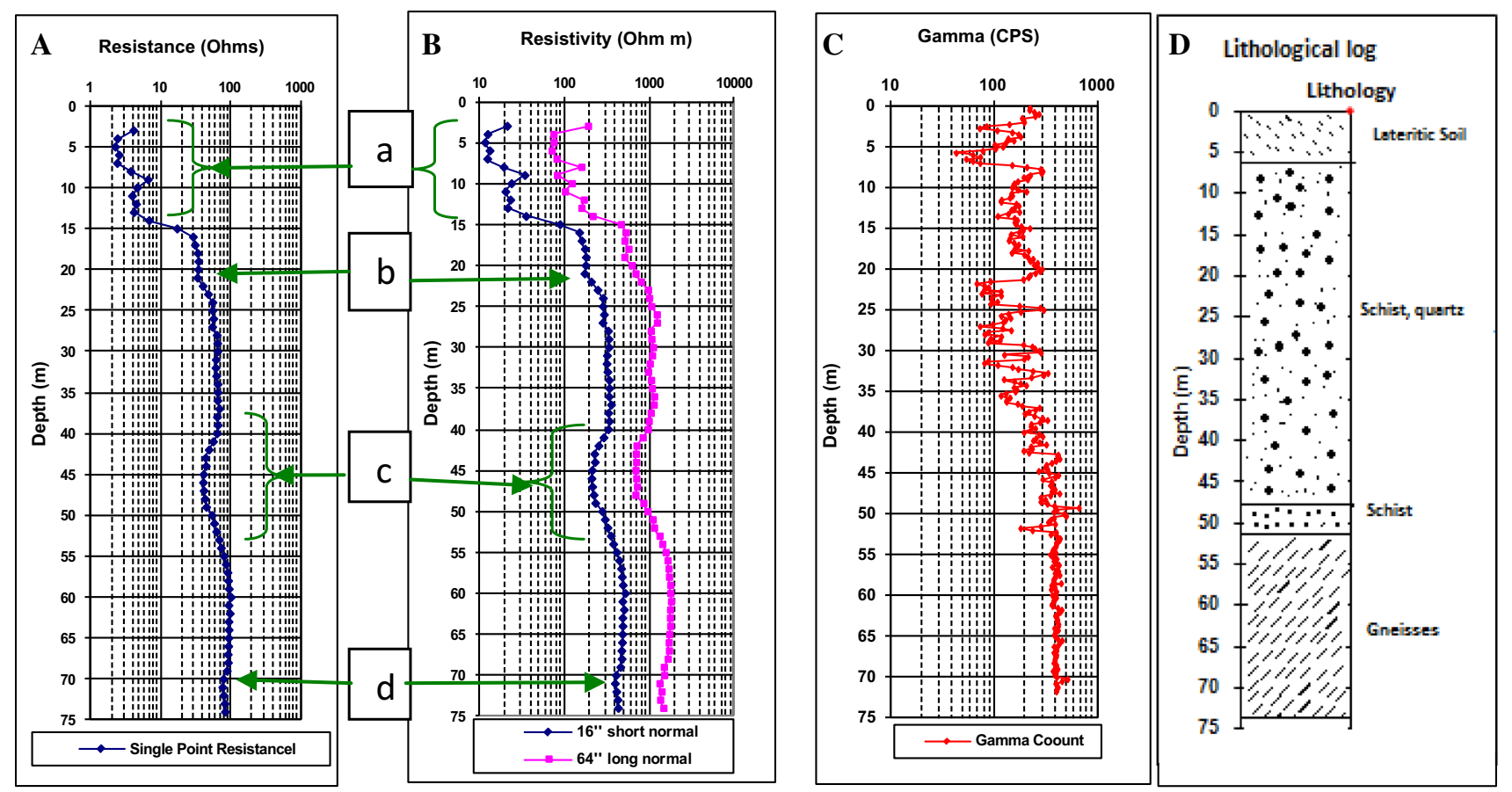

Fig. 3 Single-point resistance (a), resistivity (b), gamma (c) and lithological logs (d) for borehole BN1, GAEC

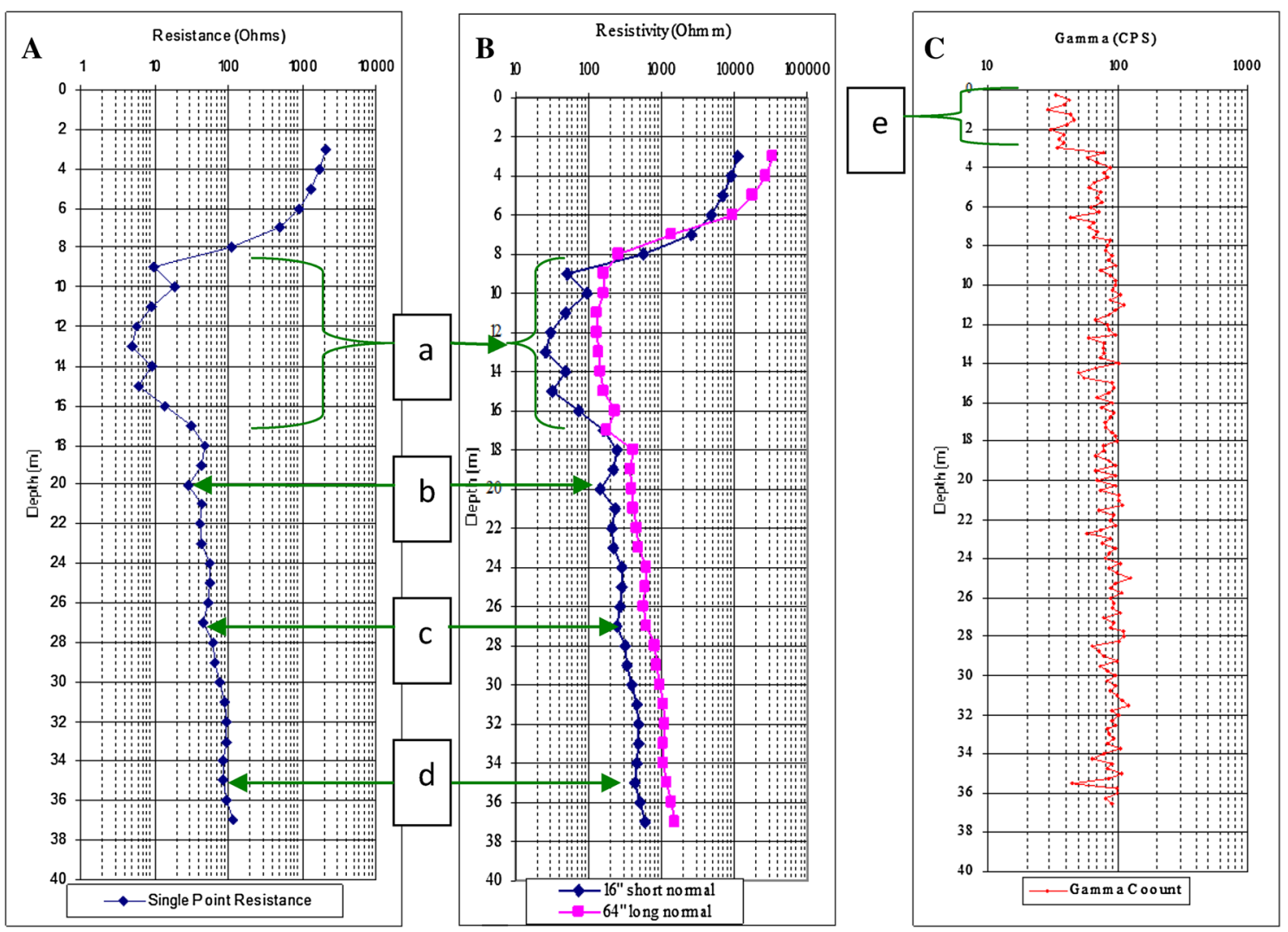

Fig. 4 Single-point resistance (a), resistivity (b) and gamma logs (c) for borehole WRI-1, WRI compound 
borehole is drilled into Dahomeyan rock. The low radiation within the uppermost $3 \mathrm{~m}$ depth marked by (e) on Fig. $4 \mathrm{c}$ is probably caused by the combination of a wider diameter and a $3 \mathrm{~m}$ long steel casing. Summarizing, the case illustrates the advantage of a gamma log for verification of the geological profile when no lithological record is available.

The three nearly uniform electrical logs indicate weathering down to approximately $16 \mathrm{~m}$ depth by showing very low resistances/resistivities to that depth, marked by (a) on Fig. 4a and b. Obviously, the weathering has not caused a change in the gamma radiation compared to the radiation pattern in the hard rock below $16 \mathrm{~m}$ depth. The high resistance/resistivity of the uppermost section above zone (a) is most probably because of the section being a dry top soil layer followed by a gradually more saturated saprock above a water table at $8 \mathrm{~m}$ depth. This explanation is based on the fact, that water was filled into the borehole just before the geophysical logging was conducted in order to be able to measure the electrical logs within the whole open rock profile.

The relatively small resistivity minima seen on the resistance log and on the $16^{\prime \prime}$ Short Normal $\log$ at 20, 27, and $35 \mathrm{~m}$ depth and marked by (b), (c) and (d) respectively on Fig. 4a and b, are interpreted as indications of fracturing/weathering because they are not corresponding with any variation on the gamma log thus not caused by any lithological change. Similar resistivity minima are hardly to be seen on the $64^{\prime \prime}$ long normal log. However, the three fractured zones are rather thin and their weathering weak. This case illustrates the advantage of having all three electrical logs, because thin fractures with weak weathering might not be seen if only the $64^{\prime \prime}$ long normal log was used.

Concerning hydro-fracturing it might be risky to try to develop the zone (b) at $20 \mathrm{~m}$ depth because of being too close to the highly weathered overburden and thereby causing risk for pressure blow-up through the nearby overburden and a subsequent collapse or inflow of soil material from the overburden.

\section{Buokrom}

The shifting lithology of the Birimian rock sequence as also shown on the litho-log Fig. $5 \mathrm{~d}$ is seen reflected by a great variation of the gamma radiation on Fig. 5c. Though, surprisingly the quartz layers shown on Fig. 5d do not always coincidence as expected with the occurring low gamma radiation sections, which indicate inaccuracy on the recorded litho-log. The weathering is recorded on the litho-log to go down to $9 \mathrm{~m}$ depth, but obviously does not affect the pattern of the gamma radiation. The thickness of the weathered mantle could not be verified by the electrical $\operatorname{logs}$, Fig. 5a and b, because they could not measure through the PVC casing pipe installed to $8 \mathrm{~m}$ depth, thus do not start until from $9 \mathrm{~m}$ depth.

All the three electrical logs show a conform pattern, but no other resistivity minimum in the solid rock below the
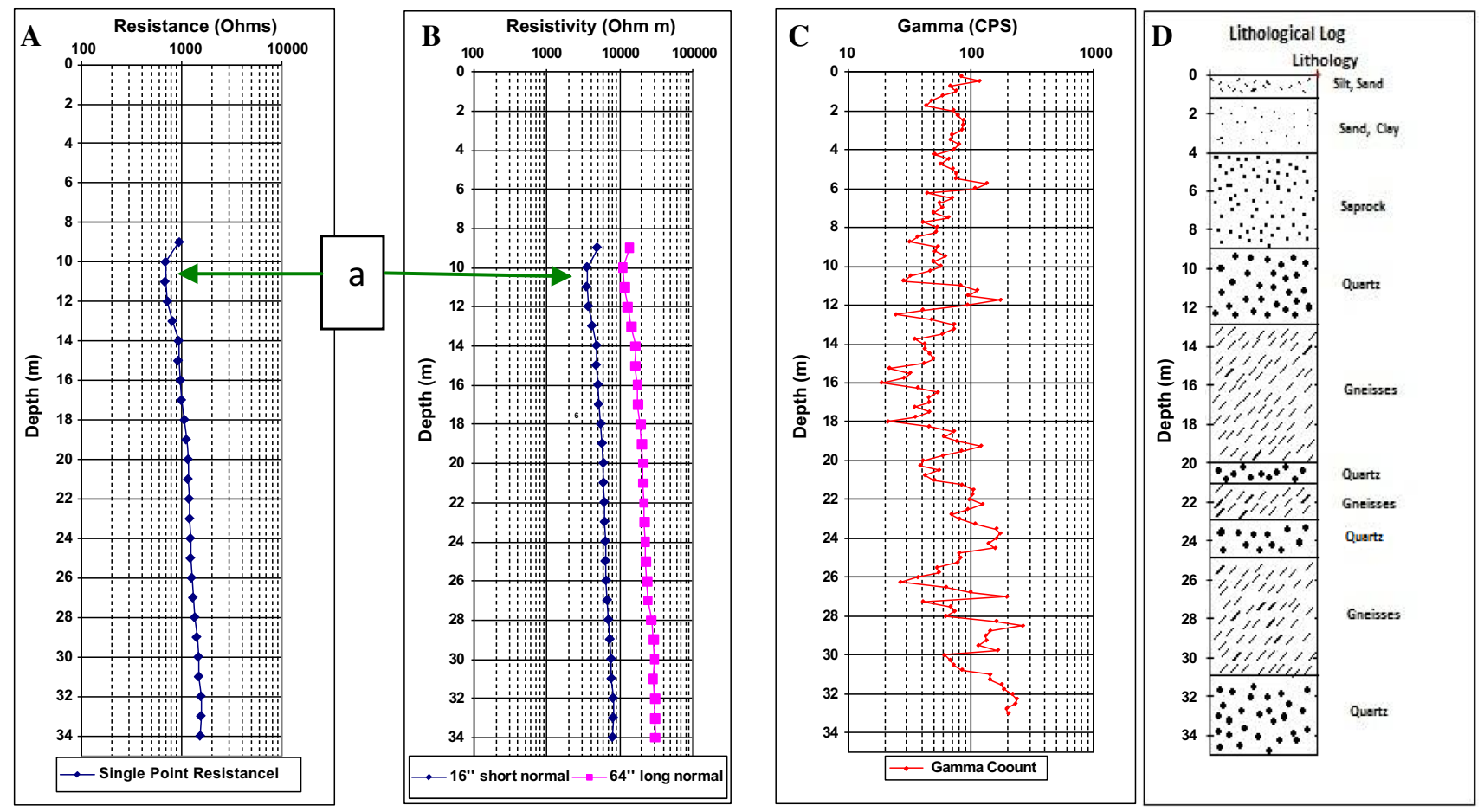

Fig. 5 Single-point resistance (a), resistivity (b), gamma (c) and lithological logs (d) for borehole BR10, Buokrom 
weathered mantle than at 10-12 m depth, marked by (a) on Fig. 5a, i.e., in the upper part of the hard rock. Since there is no corresponding gamma radiation maximum at that depth section the resistivity minimum is not due to a lithological change but an indication of fracturing/weathering. However, this is a far too shallow depth for hydrofracturing operation because of risk for pressure blow-up through the nearby overburden and a subsequent collapse or inflow of soil material from the overburden.

\section{Conclusion}

The conventional electrical logging suite such as the resistivity and SPR logs are well known for the investigation of the presence of potential water-bearing fractured zones in a geologic medium such as the crystalline basement rocks of Ghana. Gamma log has a wide application in identification of lithological boundaries of the geological material the borehole is drilled into.

This study illustrates the advantage of gamma logging for verification of the geological profile when no lithological record is available. Furthermore, the combined application of the natural gamma and conventional electrical borehole logging tools is used to identify the fracture system of boreholes drilled into various hard rock systems in the study areas for the purposes of hydrofracturing due to their low drilling yields. Based on the analysis of the combined logging results from the investigated boreholes, probable micro-fracture zones were easily delineated and selected as targets for the hydrofracturing campaign to improve their yield. Also based upon the 64" Normal resistivity values, which investigate deeper and gives the true resistivity of the subsurface geological formation, the magnitudes of the resistivity values from below the $8 \mathrm{~m}$ depth range obtained for Togo schist and quartzite was in the range of $80-2000$ Ohm- $\mathrm{m}$. The range for Acidic Dahomeyan gneiss formation was between 100 and 1500 Ohm-m, whilst that obtained for granite and its differentiated Birimian sequence ranged from 10,500 to 15,000 Ohm-m. The combined logging methods have had the advantage of locating thin fracture section and weathering zones, which could not have been identified using only one logging tool. It is therefore concluded that a combination of several logging suits has several advantages over using only one logging tool in identifying weak zone for such purposes.

Acknowledgments The authors express their appreciation, respectively to the Directors of NNRI and BNARI at GAEC and CSIR Water Research Institute (WRI), as well as to the Head of Department of Earth Science Department of University of Ghana for logistical support and allowing us to use the boreholes on their premises for this study.
Open Access This article is distributed under the terms of the Creative Commons Attribution 4.0 International License (http:// creativecommons.org/licenses/by/4.0/), which permits unrestricted use, distribution, and reproduction in any medium, provided you give appropriate credit to the original author(s) and the source, provide a link to the Creative Commons license, and indicate if changes were made.

\section{References}

Agyekum AW (2009) Application of geophysical borehole logging for hydrological studies in Northern Ghana. PhD Thesis, Department of Geology, University of Ghana

Agyekum W, Klitten K, Armah T, Banoeng-Yakubo B, Amartey EO (2013) Geophysical borehole logging for control of driller's records: hydrogeological case study from Voltaian sedimentary rocks in northern Ghana. Springer Appl Water Sci 3:491-500. doi:10.1007/s13201-013-0097-y

Ahmed SM, Blay PK, Castor SB, Coakley GJ (1977) The geology of $1 / 4^{\circ}$ field sheets nos. 33, Winneba N.E., 59, 61 and 62, Accra S.W., N. W. and N.E., Bulletin No. 32

Awini AJ (2009) Resistivity of the hard rocks in Volta region derived from pre-hydrofracturing electrical logs-importance for groundwater development. PhD Thesis, Department of Geology, University of Ghana

Banks D, Robins N (2002) An introduction to groundwater in crystalline bedrock. Geological Survey of Norway, N-7491 Trondheim Norway. ISBN 82-7386-100-1

Driscoll FG (1986) Groundwater and wells. 2nd edn. Johnson Screens, St. Paul, Minnesota, pp. 180-193

Gyau-Boakye P, Dapaah-Siakwan S (1999) Groundwater: solution to Ghana's rural water supply industry? Published in The Ghana Engineer, reprinted with GhIE permission by the African Technology Forum

Mount Sopris Instrument Co. Inc (2002a) Operation Manual for MSlog software, Golden, CO USA

Mount Sopris Instrument Co. Inc (2002b) Operation Manual for 2PGA Poly Gamma probe, Golden, CO USA

Mount Sopris Instrument Co. Inc (2002c) Operation Manual of MGX II logger, Golden, CO, USA

Junner NR, Bates DA (1945) Reports on the geology and hydrology of the coastal area east of Akwapim range Accra, Geological Survey Memoir No. 7, Ghana

Karous M, Mares S (1988) Geophysical methods in studying fracture aquifers. Charles University, Prague

Kearey P, Brooks M, Hill I (2002) An introduction to geophysical exploration, 3rd edn. Blackwell Publishing company, Blackwell Science Ltd, Smithsonian Institution Press, Cambridge, Washington, DC

Kesse GO (1985) The mineral and rock resources of Ghana. A. A. Baljema, Rotterdam

Keys WS (1997) A practical guide to borehole geophysics in environmental investigation. Lewis publishers, Boca Raton, pp 69-77

Krishnamurthy NS, Dewashish K, Ananda RV, Jain SC, Shakeel A (2003) Comparison of surface and sub-surface geophysical investigations in delineating fracture zones. Curr Sci 84(9):10

Lee C (1985) Method for locating sediment anomalies in lakebeds that can be caused by groundwater flow. J Hydrol 79:187-193

Lee DR, Milton GM, Cornett RJ, Welch SJ (1991) Location and assessment of groundwater discharge. In: Proceedings of the 2nd Annual International Conference on High Level Radioactive Waste Management, American Nuclear Society, LaGrange Park, I11, pp. 1276-1283 
MacDonald AM, Davies J (2000) A brief review of groundwater for rural water supply in sub-Saharan Africa. BGS Technical Report $\mathrm{WC} / 00 / 33$

Monier-Williams ME, Davis RK, Paillet FL, Turpening RM, Sol SJY, Schneider GW (2009) Review of borehole based geophysical site evaluation tools and techniques. Nuclear Waste Management Organization Report No. TR-2009-25, Toronto, Ontario

Ramstad RK (2004) Ground source energy in crystalline bedrockincreased energy extraction by using hydraulic fracturing in boreholes. PhD thesis. NTNU/NGU
Ratnakar D, Singh VS (2008) Identification of water-bearing fractured zones using electrical conductivity logging in granitic terrain, Andhra Pradesh, India. Curr Sci 95(8):1060-1066

Telford WM, Geldart LP, Sheriff RE (1990) Applied geophysics, 2nd edn. Cambridge University Press, Cambridge

Wright EP (1992) The hydrogeology of crystalline basement aquifers in Africa. In: Wright EP and Burgess EG (eds), Hydrogeology of Crystalline Basement Aquifers in Africa. Geol Soc Lond Spec Pub 66: 1-27 